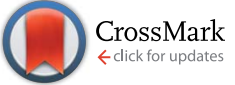

Cite this: RSC Adv., 2017, 7, 14107
Received 25th January 2017 Accepted 24th February 2017

DOI: 10.1039/c7ra01114h

rsc.li/rsc-advances

\section{Synthesis of $\mathrm{Y}_{2} \mathrm{O}_{3}: \mathrm{Bi}^{3+}, \mathrm{Eu}^{3+}$ nanosheets from layered yttrium hydroxide precursor and their photoluminescence properties $\dagger$}

\author{
Tomotaka Watanabe, Yoshiki Iso* and Tetsuhiko Isobe*
}

\begin{abstract}
We produced $\mathrm{Y}_{2} \mathrm{O}_{3}: \mathrm{Bi}^{3+}, \mathrm{Eu}^{3+}$ nanosheets by calcining layered yttrium hydroxide $(\mathrm{LYH})$ precursor nanosheets at $800{ }^{\circ} \mathrm{C}$ for $2 \mathrm{~h}$. The precursor nanosheets were synthesized from metallic chlorides dissolved in methanol, via a solvothermal reaction at $200^{\circ} \mathrm{C}$ for $2.5 \mathrm{~h}$. X-ray diffraction and transmission electron microscopy revealed that the LYH nanosheets were composed of crystallites with a uniform crystallographic orientation. Their sheet-like morphology and single-crystal nature remained after calcination, while the thickness of the nanosheets decreased. Their excitation spectrum was monitored at the $612 \mathrm{~nm}$ emission wavelength, corresponding to the ${ }^{5} \mathrm{D}_{0} \rightarrow{ }^{7} \mathrm{~F}_{2}$ transition of $\mathrm{Eu}^{3+}$, and featured a broad band at $332 \mathrm{~nm}$ that was attributed to the $6 \mathrm{~s}^{2} \rightarrow 6 \mathrm{~s} 6 \mathrm{p}$ transition of $\mathrm{Bi}^{3+}$. The $\mathrm{Y}_{2} \mathrm{O}_{3}: \mathrm{Bi}^{3+}, \mathrm{Eu}^{3+}$ nanosheets therefore exhibited red emission from $\mathrm{Eu}^{3+}$ via energy transfer from $\mathrm{Bi}^{3+}$ to $\mathrm{Eu}^{3+}$ following near-UV excitation of $\mathrm{Bi}^{3+}$. The photoluminescence (PL) properties of the calcined samples were investigated with various concentrations of $\mathrm{Bi}^{3+}$ in $\mathrm{Y}_{2} \mathrm{O}_{3}$ nanosheets codoped with 2 at\% $\mathrm{Eu}^{3+}$. The highest $\mathrm{PL}$ quantum yield was $23 \%$ at a $\mathrm{Bi}^{3+}$ concentration of 0.2 at $\%$. The $\mathrm{PL}$ lifetimes of the calcined samples decreased with increasing $\mathrm{Bi}^{3+}$ concentration due to concentration quenching. The $\mathrm{PL}$ intensity increased over time under continuous excitation, which might be attributable to the photooxidation of $\mathrm{Bi}$ following its reduction by polyethyleneimine or methanol during the LYH synthesis.
\end{abstract}

\section{Introduction}

$\mathrm{Y}_{2} \mathrm{O}_{3}$ doped with $\mathrm{Eu}^{3+}\left(\mathrm{Y}_{2} \mathrm{O}_{3}: \mathrm{Eu}^{3+}\right)$ shows strong red emission under ultraviolet (UV) light via the charge-transfer transition of $\mathrm{O}^{2-} \rightarrow \mathrm{Eu}^{3+} \cdot{ }^{1-3}$ It is well known that the codopant $\mathrm{Bi}^{3+}$ acts as a sensitizer for $\mathrm{Eu}^{3+}$ via energy transfer from $\mathrm{Bi}^{3+}$ to $\mathrm{Eu}^{3+}$ following the $6 \mathrm{~s}^{2} \rightarrow 6 \mathrm{~s} 6 \mathrm{p}$ transition of $\mathrm{Bi}^{3+}$ under near-UV excitation. ${ }^{4-6} \mathrm{Y}_{2} \mathrm{O}_{3}$ codoped with $\mathrm{Bi}^{3+}$ and $\mathrm{Eu}^{3+}\left(\mathrm{Y}_{2} \mathrm{O}_{3}: \mathrm{Bi}^{3+}, \mathrm{Eu}^{3+}\right)$ therefore shows red emission from $\mathrm{Eu}^{3+}$ excited by near-UV excitation at wavelengths of around $300-400 \mathrm{~nm} . \mathrm{Y}_{2} \mathrm{O}_{3}: \mathrm{Bi}^{3+}, \mathrm{Eu}^{3+}$ has attracted attentions for an application to wavelengthconversion material in white light-emitting diodes, ${ }^{7}$ while $\mathrm{Y}_{2} \mathrm{O}_{3}: \mathrm{Eu}^{3+}$ had been used in the traditional cathode ray tube. ${ }^{8}$

Department of Applied Chemistry, Faculty of Science and Technology, Keio University, 3-14-1 Hiyoshi, Kohoku-ku, Yokohama 223-8522, Japan. E-mail: iso@applc.keio.ac.jp; isobe@applc.keio.ac.jp; Fax: +8145566 1551; Tel: +81 45566 1558; +81 455661554 $\dagger$ Electronic supplementary information (ESI) available: TG-DTA thermograms of undoped, 10 at $\% \mathrm{Bi}^{3+}$-doped, and 2 at $\% \mathrm{Eu}^{3+}$-doped precursors (Fig. S1); high-precision (220) XRD peaks and (222) XRD peaks of undoped, 10 at $\%$ $\mathrm{Bi}^{3+}$-doped, 2 at $\% \mathrm{Eu}^{3+}$-doped, and $\mathrm{Bi}^{3+}$, $\mathrm{Eu}^{3+}$-codoped $\mathrm{LYH}$ precursors and $\mathrm{Y}_{2} \mathrm{O}_{3}$ samples, respectively (Fig. S2); calculated $d$-spacings and crystallite sizes from Fig. S2 (Tables S1 and S2); AFM images of an LYH precursor nanosheet and a $\mathrm{Y}_{2} \mathrm{O}_{3}$ nanosheet, codoped with 10 at $\% \mathrm{Bi}^{3+}$ and 2 at $\% \mathrm{Eu}^{3+}$ (Fig. S3); XRD profiles, atomic compositions determined by XRF, and PL and PLE spectra of $x$ at $\% \mathrm{Bi}^{3+}, 2$ at $\% \mathrm{Eu}^{3+}$-codoped $\mathrm{Y}_{2} \mathrm{O}_{3}$ samples (Fig. S4, Table S3, and Fig. S5, respectively). See DOI: $10.1039 / \mathrm{c} 7 \mathrm{ra} 01114 \mathrm{~h}$
In recent years, one of the potential applications of phosphors such as these, which absorb near-UV light, is as a spectral converter to improve the photoelectric conversion efficiency of solar cells. ${ }^{9-13}$ The sensitivity of commercial silicon solar modules is low in the UV region because of reflection and absorption by encapsulation materials. ${ }^{13}$ Thermalization losses following the absorption of photons with excess energy also reduce the sensitivity. ${ }^{\mathbf{1 4}}$ A spectral converter converts near-UV light to visible light, from which the solar modules can generate electricity more efficiently. The fluorescent film used for spectral converters requires transparency in the visible range to prevent the loss of visible sunlight. In addition, the phosphors for spectral converters must have high stability under sunlight, i.e., light-fastness and thermal stability. Inorganic nanophosphors, such as $\mathrm{YVO}_{4}: \mathrm{Bi}^{3+}, \mathrm{Eu}^{3+}$ nanoparticles, can satisfy those requirements. $\mathrm{YVO}_{4}: \mathrm{Bi}^{3+}, \mathrm{Eu}^{3+}$ nanoparticles, which show red emission under near-UV excitation, exhibit high transparency because of their low light-scattering loss. Previously, we reported transparent films fabricated by dispersing $\mathrm{YVO}_{4}: \mathrm{Bi}^{3+}, \mathrm{Eu}^{3+}$ nanoparticles in a polyurethane matrix. ${ }^{15}$ The fabricated films could convert near-UV light to red light and had high transparency in the visible range. However, exposure to near-UV irradiation also decreased the photoluminescence (PL) intensity of the films. Under near-UV excitation, $\mathrm{YVO}_{4}: \mathrm{Bi}^{3+}, \mathrm{Eu}^{3+}$ reacted photochemically with the polyurethane matrix and with 
citrate ions adsorbed on the surfaces of the nanoparticles, which resulted in the reduction of $\mathrm{V}^{5+}$ to $\mathrm{V}^{4+} \cdot{ }^{16-18}$

In contrast to $\mathrm{YVO}_{4}: \mathrm{Bi}^{3+}, \mathrm{Eu}^{3+}$ nanoparticles, $\mathrm{Y}_{2} \mathrm{O}_{3}: \mathrm{Bi}^{3+}, \mathrm{Eu}^{3+}$ is composed of chemically stable ions. In addition, $\mathrm{Y}_{2} \mathrm{O}_{3}$ is not semiconductive, which means it does not behave as a photocatalyst under near-UV irradiation. It is reported that $\mathrm{Y}_{2} \mathrm{O}_{3}: \mathrm{Eu}^{3+}$ nanosheets can be obtained via the calcination of yttrium hydroxides, and that they are suitable for transparent phosphor films. ${ }^{19}$ For those reasons, $\mathrm{Y}_{2} \mathrm{O}_{3}: \mathrm{Bi}^{3+}, \mathrm{Eu}^{3+}$ nanosheets represent a promising material for spectral converters.

$\mathrm{Y}_{2} \mathrm{O}_{3}: \mathrm{Eu}^{3+}$ nanophosphors have mostly been produced via the calcination of precursors., ${ }^{\mathbf{1 , 2}, 20-22}$ Recently, $\mathrm{Y}_{2} \mathrm{O}_{3}: \mathrm{Eu}^{3+}$ nanosheets prepared from layered rare earth hydroxide $\left(\mathrm{LRH} ; \mathrm{RE}_{2}(\mathrm{OH})_{5^{-}}\right.$ $\mathrm{A} \cdot n \mathrm{H}_{2} \mathrm{O} ; \mathrm{RE}=\mathrm{Y}, \mathrm{Eu}, \mathrm{A}=$ free anions) were reported..$^{23}$ LRHs contain host layers composed of planar rare earth hydroxides, with $\mathrm{H}_{2} \mathrm{O}$ molecules and free anions intercalated in the interlayers. ${ }^{24}$ The host layer is a close-packed crystal plane, so LRHs tend to become nanosheets through crystallization along the (001) plane. ${ }^{25}$ Furthermore, [111]-oriented oxide nanosheets can be obtained from the corresponding [001]-oriented LRH nanosheets via quasi-topotactic transformation under calcinations. ${ }^{26}$ Highly [111]-oriented and transparent rare earth oxide films can be fabricated by the deposition of LRH nanosheets onto a substrate followed by calcinations..$^{24,27,28}$ LRH nanosheets have drawn attention as precursors for highly oriented and transparent films.

Very recently, we fabricated $\mathrm{Y}_{2} \mathrm{O}_{3}: \mathrm{Bi}^{3+}, \mathrm{Eu}^{3+}$ nanosheets using nitrates as the starting reagents, and these nanosheets showed high photostability under near-UV excitation. ${ }^{29}$ In the synthesis, ethylene glycol was used as a solvent for bismuth nitrate $\left(\mathrm{Bi}\left(\mathrm{NO}_{3}\right)_{3} \cdot 5 \mathrm{H}_{2} \mathrm{O}\right)$ because bismuth nitrate is not soluble in water. The concentration of $\mathrm{Bi}^{3+}$ in the $\mathrm{Y}_{2} \mathrm{O}_{3}: \mathrm{Bi}^{3+}, \mathrm{Eu}^{3+}$ nanosheets was lower than the nominal value, probably because of the high stability of bismuth ions coordinated with ethylene glycol. In the present work, we chose bismuth chloride $\left(\mathrm{BiCl}_{3}\right)$ as an alternative bismuth source. Although bismuth chloride is only sparingly soluble in alcohols under ambient conditions, its solubility is increased under the high-temperature conditions of solvothermal synthesis. In the present work, we synthesized nanosheets of layered yttrium hydroxide codoped with $\mathrm{Bi}^{3+}$ and $\mathrm{Eu}^{3+}$ (LYH:$\left.\mathrm{Bi}^{3+}, \mathrm{Eu}^{3+}\right)$ in a mixture of chlorides in methanol and a polyethyleneimine (PEI) aqueous solution, inside an autoclave. We then synthesized $\mathrm{Y}_{2} \mathrm{O}_{3}: \mathrm{Bi}^{3+}, \mathrm{Eu}^{3+}$ nanosheets via the calcination of these LYH precursors, and measured their photoluminescent properties.

\section{Experimental section}

\subsection{Materials}

$\mathrm{YCl}_{3} \cdot 6 \mathrm{H}_{2} \mathrm{O}$ (99.99\%), $\mathrm{BiCl}_{3}$ (99.5\%), and methanol (99.8\%) were purchased from Kanto Chemical. $\mathrm{EuCl}_{3} \cdot 6 \mathrm{H}_{2} \mathrm{O}(99.9 \%)$ was purchased from Soekawa Chemical. PEI $\left(M_{\mathrm{w}}=25000,99 \%\right)$ was purchased from Sigma-Aldrich. All reagents were used without further purification.

\subsection{Preparation of precursors and calcined sample}

$\mathrm{YCl}_{3} \cdot 6 \mathrm{H}_{2} \mathrm{O}, \mathrm{EuCl}_{3} \cdot 6 \mathrm{H}_{2} \mathrm{O}$, and $\mathrm{BiCl}_{3}$ (total $0.5 \mathrm{mmol}, \mathrm{Eu}=2$ at $\%, \mathrm{Bi}=0.1-10$ at $\%$ ) were added to $16 \mathrm{~mL}$ of methanol. Then, the mixture was added into $5 \mathrm{~mL}$ of $2 \mathrm{wt} \%$ PEI aqueous solution. The resulting suspension was placed in a Teflon vessel with a volume of $50 \mathrm{~mL}$ and heated in a stainless steel autoclave (Berghof, DAB-2) at $200{ }^{\circ} \mathrm{C}$ for $2.5 \mathrm{~h}$. After cooling to room temperature, the precipitate was isolated by washing with ethanol, followed by $5 \mathrm{~min}$ of centrifugation at $11000 \times g$ (10 $000 \mathrm{rpm}$ using a rotor with a diameter of $10 \mathrm{~cm}$ ). This cycle of washing and centrifugation was performed twice. The precipitate was then dried at $60{ }^{\circ} \mathrm{C}$ for $5 \mathrm{~h}$ to obtain a precursor codoped with $\mathrm{Bi}^{3+}$ and $\mathrm{Eu}^{3+}$. An undoped precursor, as well as precursors singly doped with either $\mathrm{Bi}^{3+}$ or $\mathrm{Eu}^{3+}$, were also prepared by the same procedure. The precursors were heated to $800{ }^{\circ} \mathrm{C}$ at a heating rate of $10^{\circ} \mathrm{C} \mathrm{min}^{-1}$ in an air flow of 300 $\mathrm{mL} \min ^{-1}$, and kept at that temperature for $2 \mathrm{~h}$ to obtain the calcined samples.

\subsection{Characterization}

Thermal analysis was performed using a thermogravimetry and differential thermal analysis (TG-DTA) instrument (Thermo Plus-8120, Rigaku) at a heating rate of $10{ }^{\circ} \mathrm{C} \mathrm{min}^{-1}$ in

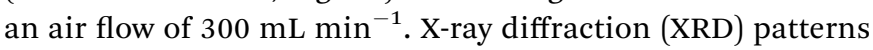
were measured on an X-ray diffractometer (Rint-2200, Rigaku) with a $\mathrm{Cu} \mathrm{K} \alpha$ radiation source and monochromator. Elemental compositions were determined by the fundamental parameter method using an X-ray fluorescence (XRF) analyzer (ZFX mini II, Rigaku). Particles were observed with a transmission electron microscope (TEM; Tecnai $\mathrm{G}^{2}$ and Tecnai 12, FEI). The samples for TEM were prepared by drying a drop of a methanol dispersion of each sample on a carbonreinforced collodion film of a copper grid. The topographies of the nanosheets were observed with an atomic force microscope (AFM; AFM5100N, Hitachi) in dynamic mode using a cantilever (Pointprobe NCHR, Nano world). The samples for AFM were prepared by drying a drop of a methanol dispersion of each sample on a negative-type silicon wafer. PL and photoluminescence excitation (PLE) spectra were recorded on a fluorescence spectrometer (FP-6500, JASCO). Changes in PL intensity during continuous near-UV excitation were measured with the same apparatus. Each spectral response was calibrated using an ethylene glycol solution of Rhodamine B (5.5 $\left.\mathrm{g} \mathrm{L}^{-1}\right)$ and a standard light source (ESC-333, JASCO). The PL quantum yield (QY), $\Phi$, was measured on the same spectrometer equipped with an integrating sphere (ISF-513, JASCO), based on the following equation:

$$
\Phi=\frac{I_{\mathrm{em}}}{I_{\mathrm{ex}}-I_{\mathrm{ref}}}
$$

where $I_{\mathrm{em}}$ is the integrated emission intensity of the sample, $I_{\mathrm{ex}}$ is the integrated intensity of the incident excitation light, and $I_{\text {ref }}$ is the integrated intensity of the excitation light reflected by the sample. A reflectance standard (Spectralon SRS-99, Labsphere) was used to determine $I_{\mathrm{ex}}$. PL decay curves were recorded on a fluorescent lifetime spectrometer (Quantaurus-Tau C11367, Hamamatsu Photonics) using a Xe flash lamp with a band path filter of $365 \mathrm{~nm}$. 


\section{Results and discussion}

\subsection{Particulate and structural properties of precursors and of samples calcined at $800{ }^{\circ} \mathrm{C}$}

The TG-DTA profiles (Fig. 1) of the precursor codoped with 10 at $\% \mathrm{Bi}^{3+}$ and 2 at $\% \mathrm{Eu}^{3+}$ show the endothermic weight loss proceeding in three steps, which are similar to those previously observed for $\mathrm{Ln}_{2}(\mathrm{OH})_{5} \mathrm{NO}_{3} \cdot n \mathrm{H}_{2} \mathrm{O} .^{23,30}$ In the case of $\mathrm{Y}_{2}(\mathrm{OH})_{5}-$ $\mathrm{Cl} \cdot n \mathrm{H}_{2} \mathrm{O}$ herein, the first step, occurring below $145{ }^{\circ} \mathrm{C}$, corresponds to the evaporation of co-intercalated water. The second step, at $300{ }^{\circ} \mathrm{C}$, corresponds to the dehydration of the host layers. The third step, at $800^{\circ} \mathrm{C}$, corresponds to the evaporation of intercalated anions. The third step occurred at a higher temperature than for $\mathrm{Ln}_{2}(\mathrm{OH})_{5} \mathrm{NO}_{3} \cdot n \mathrm{H}_{2} \mathrm{O}$, possibly because of the higher charge density of chloride ions. All the precursors showed qualitatively similar TG-DTA thermograms (Fig. S1†).

The XRD patterns (Fig. 2) of all the precursors were indexed to orthorhombic $\mathrm{Y}_{2}(\mathrm{OH})_{5} \mathrm{Cl} \cdot n \mathrm{H}_{2} \mathrm{O}$, as reported by Liang et al. ${ }^{31}$ The high-precision XRD profiles (Fig. S2(A) and Table S1†) indicated a shift of the (220) reflection to the lower-angle side in the doped samples. This indicates an expansion of the metal-tometal distances in the LYH host layers ${ }^{23}$ caused by the substitution of $\mathrm{Bi}^{3+}$ and $\mathrm{Eu}^{3+}$ (with their larger ionic radii) for $\mathrm{Y}^{3+}$. The crystallite sizes of the precursors, calculated from the widths of the (220) reflection peaks using the Scherrer equation, were approximately $60-70 \mathrm{~nm}$. The TEM images revealed that all the precursors obtained after autoclaving possessed an elongated sheet-like shape, as shown in panels (a)-(d) of Fig. 3. The lateral sizes of the nanosheets were on the order of hundreds of nanometers. The crystallite sizes determined from the (220) reflection peaks were thus smaller than the lateral sizes, indicating that the precursors were polycrystalline. The thickness of the nanosheets measured by AFM (Fig. S3(A) $\dagger$ ) was $40 \mathrm{~nm}$, which corresponds to $\sim 50$ layers. Panel (b) of Fig. 4 shows a selected-area electron diffraction (SAED) image of one $\mathrm{Bi}^{3+}, \mathrm{Eu}^{3+}$-codoped precursor nanosheet (panel (a) of Fig. 4), which exhibits a spot pattern of LYH. ${ }^{32}$ This indicates that each nanosheet was composed of crystallites with a uniform crystallographic orientation; i.e., they had a single-crystal nature.



Fig. 1 TG-DTA thermograms of the 10 at $\% \mathrm{Bi}^{3+}, 2$ at $\% \mathrm{Eu}^{3+}$-codoped precursor.

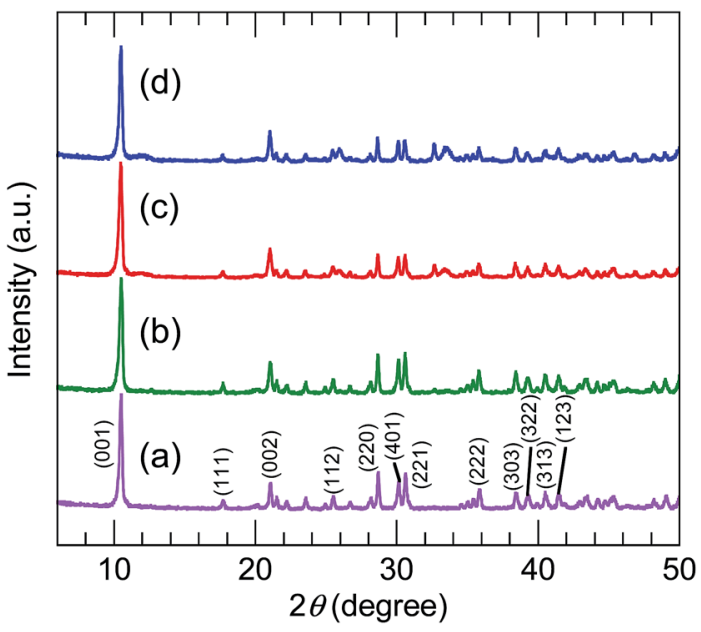

Fig. 2 XRD profiles of (a) undoped, (b) 10 at $\% \mathrm{Bi}^{3+}$-doped, (c) 2 at $\%$ $\mathrm{Eu}^{3+}$-doped, and (d) 10 at $\% \mathrm{Bi}^{3+}, 2$ at $\% \mathrm{Eu}^{3+}$-codoped precursors.

The high-resolution TEM image of the selected nanosheet (panel (c) of Fig. 4) showed lattice fringes representing the (220) plane, with a spacing of $0.31 \mathrm{~nm}$. The fast Fourier transform (FFT) image in panel (d) of Fig. 4 is similar to the SAED pattern.

Table 1 shows the metallic compositions of the precursors as measured by XRF. The measured Eu contents of the $\mathrm{Bi}^{3+}, \mathrm{Eu}^{3+}-$ codoped and $\mathrm{Eu}^{3+}$-doped precursors were larger than their nominal contents, while the measured $\mathrm{Y}$ contents of both precursors were smaller than their nominal contents. The measured Bi content of the $\mathrm{Bi}^{3+}, \mathrm{Eu}^{3+}$-codoped precursor, 8.4 at $\%$, was smaller than the nominal content (10 at\%), while that of the $\mathrm{Bi}^{3+}$-doped precursor, 14.3 at $\%$, was larger than the nominal content (10 at\%). In our previous research, in which metallic nitrates were used as starting materials, the $\mathrm{Bi}^{3+}$-doped and $\mathrm{Bi}^{3+}, \mathrm{Eu}^{3+}$-codoped precursors with nominal Bi contents of 10 at $\%$ had measured Bi contents of 2.8 and 3.4 at\%, respectively, ${ }^{29}$ both smaller than those in this work. In that study, bismuth nitrate was dissolved in ethylene glycol, to allow $\mathrm{Bi}^{3+}$ to form a stable complex in solution and prevent $\mathrm{Bi}^{3+}$ ions from precipitating. In summary, the XRF results show that precursors with the desired Bi contents can be easily synthesized by our proposed method, in which metallic chlorides are used as starting materials. This method therefore enables research into the effect of the Bi content on the morphological characteristics and PL properties of nanosheets.

The XRD patterns of the samples calcined at $800{ }^{\circ} \mathrm{C}$ (Fig. 5) were consistent with pure-phase cubic $\mathrm{Y}_{2} \mathrm{O}_{3}$. The high-precision XRD profiles (Fig. S2(B) and Table S2 $\dagger$ ) indicated a shift of the (222) reflection to the lower-angle side in the doped samples. This indicates an expansion of the $d$-spacing of the (222) facets caused by the substitution of $\mathrm{Bi}^{3+}$ and $\mathrm{Eu}^{3+}$ (with their larger ionic radii) for $\mathrm{Y}^{3+}$. The crystallite size of the nanosheets, calculated from the width of the (222) reflection peak using the Scherrer equation, was 19-20 $\mathrm{nm}$. The TEM images of the samples calcined at $800{ }^{\circ} \mathrm{C}$ (panels (e)-(h) of Fig. 3) revealed that the elongated nanosheets remained unchanged after calcination, while the thickness of the nanosheets obtained by AFM (Fig. S3 $†$ ) decreased from $40 \mathrm{~nm}$ to $25 \mathrm{~nm}$. Panel (b) of Fig. 6 shows an 


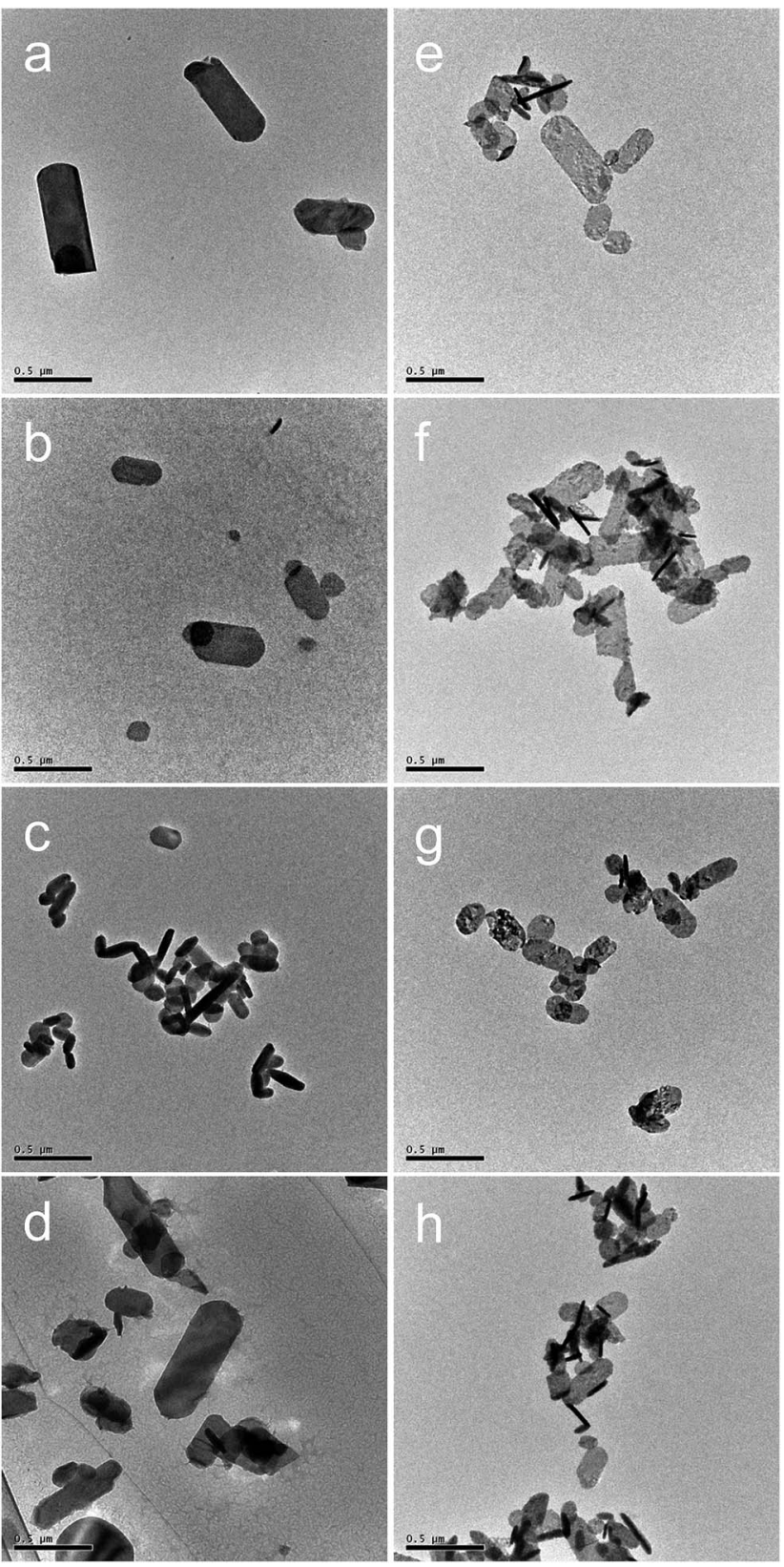

Fig. 3 TEM images of $(a-d)$ precursors and $(e-h)$ samples calcined at $800{ }^{\circ} \mathrm{C}$ for $2 \mathrm{~h}$ with different dopants: $(\mathrm{a}, \mathrm{e})$ undoped, (b, f) 10 at $\% \mathrm{Bi}^{3+}$ doped, (c, g) 2 at\% $\mathrm{Eu}^{3+}$-doped, and (d, h) 10 at $\% \mathrm{Bi}^{3+}, 2$ at $\% \mathrm{Eu}^{3+}$ codoped. Scale bar: $0.5 \mu \mathrm{m}$.

SAED image of one $\mathrm{Y}_{2} \mathrm{O}_{3}: \mathrm{Bi}^{3+}, \mathrm{Eu}^{3+}$ nanosheet (panel (a) of Fig. 6), which also exhibits a spot pattern. This indicates that the nanosheets retained their single-crystal nature. The highresolution TEM image of the selected nanosheet (panel (c) of Fig. 6) showed lattice fringes representing the (211) plane of cubic $\mathrm{Y}_{2} \mathrm{O}_{3}$, with a spacing of $0.43 \mathrm{~nm}$. The FFT image in panel (d) of Fig. 6 also exhibits a spot pattern corresponding to cubic $\mathrm{Y}_{2} \mathrm{O}_{3}$.

\subsection{PL properties of samples calcined at $800{ }^{\circ} \mathrm{C}$}

Fig. 7 shows the PL and PLE spectra of the samples calcined at $800{ }^{\circ} \mathrm{C}$. The $\mathrm{Y}_{2} \mathrm{O}_{3}: \mathrm{Bi}^{3+}$ nanosheets showed broad emission at

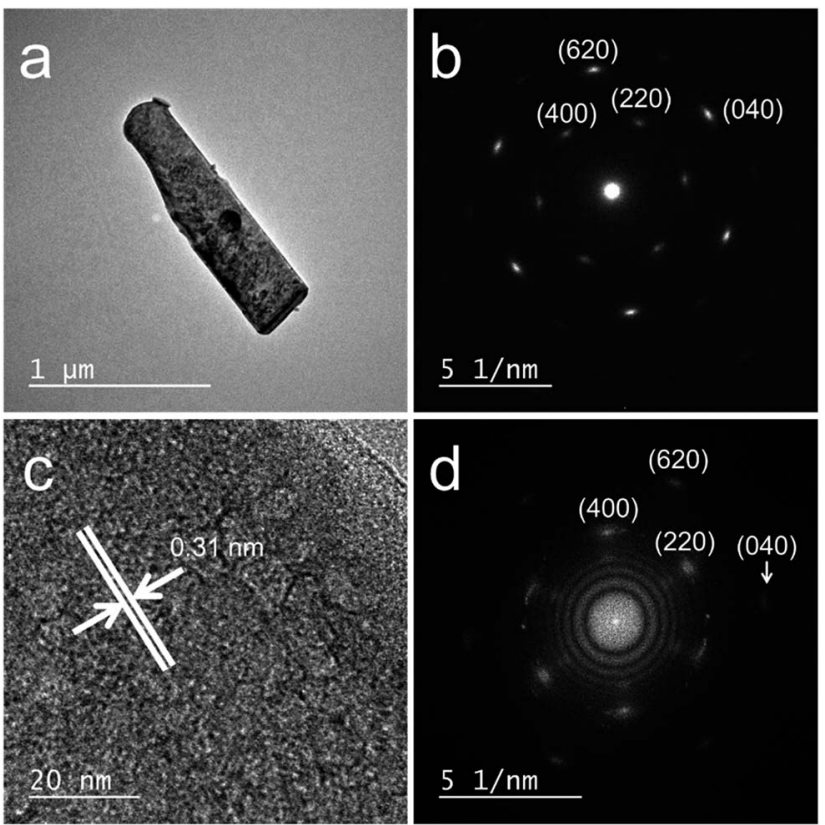

Fig. 4 (a) TEM image, (b) SAED pattern, (c) high-resolution TEM image, and (d) FFT image of a 10 at $\mathrm{Bi}^{3+}, 2$ at $\% \mathrm{Eu}^{3+}$-codoped precursor nanosheet.

Table 1 Atomic compositions of precursors and calcined samples determined by XRF

\begin{tabular}{lllll}
\hline Dopant(s) & Sample & Y (at\%) & Bi (at\%) & Eu (at\%) \\
\hline $\mathrm{Eu}^{3+}$ & Nominal & 98.0 & 0.0 & 2.0 \\
& Precursor & 91.3 & 0.0 & 8.7 \\
$\mathrm{Bi}^{3+}$ & Calcined & 94.4 & 0.0 & 5.6 \\
& Nominal & 90.0 & 10.0 & 0.0 \\
& Precursor & 85.7 & 14.3 & 0.0 \\
$\mathrm{Bi}^{3+}, \mathrm{Eu}^{3+}$ & Calcined & 88.7 & 11.3 & 0.0 \\
& Nominal & 88.0 & 10.0 & 2.0 \\
& Precursor & 85.8 & 8.4 & 5.8 \\
& Calcined & 86.2 & 9.0 & 4.8
\end{tabular}

$502 \mathrm{~nm}$ under excitation at $332 \mathrm{~nm}$, arising from the transition between the $6 \mathrm{~s}^{2}$ and $6 \mathrm{~s} 6 \mathrm{p}$ orbitals of $\mathrm{Bi}^{3+}{ }^{2}$ For the $\mathrm{Y}_{2} \mathrm{O}_{3}: \mathrm{Eu}^{3+}$ nanosheets, sharp emission peaks corresponding to the ${ }^{5} \mathrm{D}_{0} \rightarrow$ ${ }^{7} \mathrm{~F}_{J}(J=1-4)$ transitions of $\mathrm{Eu}^{3+}$ were observed at 593, 612, 652, and $710 \mathrm{~nm}$, respectively, under excitation at $234 \mathrm{~nm}$, arising from $\mathrm{O}^{2-} \rightarrow \mathrm{Eu}^{3+}$ charge transfer. ${ }^{3}$ For the $\mathrm{Y}_{2} \mathrm{O}_{3}: \mathrm{Bi}^{3+}, \mathrm{Eu}^{3+}$ nanosheets, a strong ${ }^{5} \mathrm{D}_{0} \rightarrow{ }^{7} \mathrm{~F}_{2}$ emission from $\mathrm{Eu}^{3+}$ was observed at $612 \mathrm{~nm}$ under $332 \mathrm{~nm}$ excitation. This arose from the energy transfer from excited $\mathrm{Bi}^{3+}$ to $\mathrm{Eu}^{3+} .{ }^{4} \mathrm{Y}_{2} \mathrm{O}_{3}$ contains two distinct cation sites with different symmetries $\left(S_{6}\right.$ and $\left.C_{2}\right)$. The ${ }^{5} \mathrm{D}_{0} \rightarrow{ }^{7} \mathrm{~F}_{2}$ transition of $\mathrm{Eu}^{3+}$ is forbidden under inversion symmetry, so the ${ }^{5} \mathrm{D}_{0} \rightarrow{ }^{7} \mathrm{~F}_{2}$ emission of the $\mathrm{Y}_{2} \mathrm{O}_{3}: \mathrm{Bi}^{3+}, \mathrm{Eu}^{3+}$ nanosheets must be predominantly attributed to $\mathrm{Eu}^{3+}$ ions at the $C_{2}$ sites and at sites on the surface without inversion symmetry.

The PL QY of the calcined sample codoped with 10 at $\% \mathrm{Bi}^{3+}$ and 2 at $\% \mathrm{Eu}^{3+}$ was less than $1 \%$. It is known that concentration quenching occurs when the Bi content exceeds a certain level. 




Fig. 5 XRD profiles of (a) undoped, (b) 10 at\% Bi ${ }^{3+}$-doped, (c) 2 at\% $\mathrm{Eu}^{3+}$-doped, and (d) 10 at\% $\mathrm{Bi}^{3+}, 2$ at\% $\mathrm{Eu}^{3+}$-codoped calcined samples.

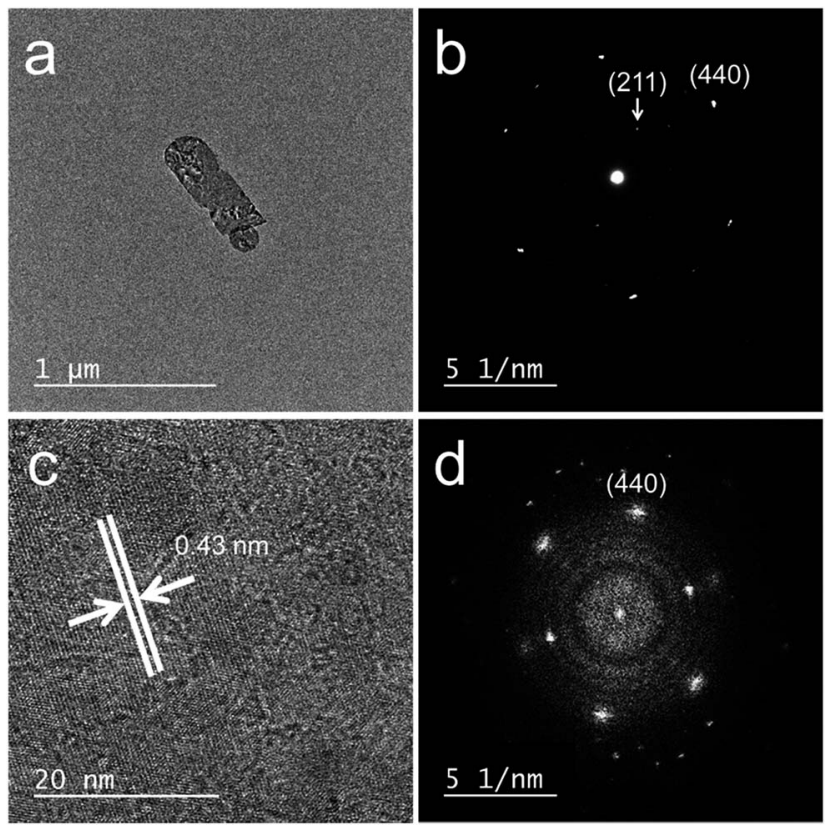

Fig. 6 (a) TEM image, (b) SAED pattern, (c) high-resolution TEM image, and (d) FFT image of a 10 at $\% \mathrm{Bi}^{3+}, 2$ at $\% \mathrm{Eu}^{3+}$-codoped calcined nanosheet.

Therefore, a series of samples with lower concentrations of $\mathrm{Bi}$ (0.1-10 at\%), each codoped with Eu at a fixed concentration of 2 at $\%$, was synthesized. All of these samples had the same crystal structure, belonging to cubic $\mathrm{Y}_{2} \mathrm{O}_{3}$, and their $\mathrm{Bi}$ and $\mathrm{Eu}$ concentrations were found to be close to the nominal values (Fig. S4 and Table S3†). The samples with different Bi concentrations exhibited PL and PLE peaks with the same shapes but different intensities (Fig. S5 $\dagger$ ). Fig. 8 shows the variation in the PL QY of the calcined $\mathrm{Bi}^{3+}, \mathrm{Eu}^{3+}$-codoped samples as a function of the nominal Bi concentration.

The highest PL QY was 23\%, for the sample with a $\mathrm{Bi}$ concentration of 0.2 at $\%$. The decay characteristics of the
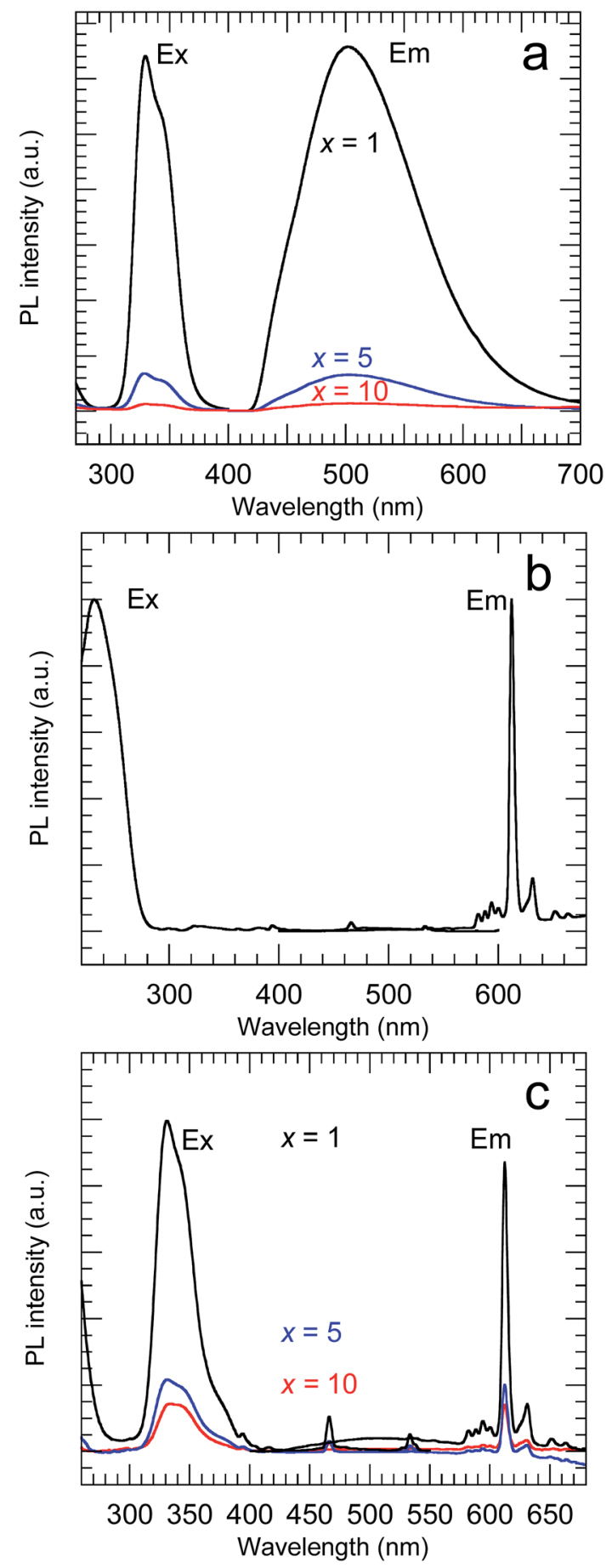

Fig. $7 \mathrm{PL}$ and PLE spectra of (a) $x$ at\% $\mathrm{Bi}^{3+}$-doped, (b) 2 at\% $\mathrm{Eu}^{3+}$ doped and (c) $x$ at\% $\mathrm{Bi}^{3+}, 2$ at\% $\mathrm{Eu}^{3+}$-codoped calcined samples. (a) $\lambda_{\mathrm{ex}}=332 \mathrm{~nm}$ and $\lambda_{\mathrm{em}}=502 \mathrm{~nm}$, (b) $\lambda_{\mathrm{ex}}=210 \mathrm{~nm}$ and $\lambda_{\mathrm{em}}=612 \mathrm{~nm}$, (c) $\lambda_{\mathrm{ex}}=332 \mathrm{~nm}$ and $\lambda_{\mathrm{em}}=612 \mathrm{~nm}$.

calcined samples also showed a dependence on the $\mathrm{Bi}^{3+}$ concentration, as shown in Fig. 9 and Table 2. The PL decay curves for the $612 \mathrm{~nm}$ emission from $\mathrm{Eu}^{3+}$ can be well fitted by eqn (2):

$$
I=A_{1} \exp \left(-t / \tau_{1}\right)+A_{2} \exp \left(-t / \tau_{2}\right)
$$




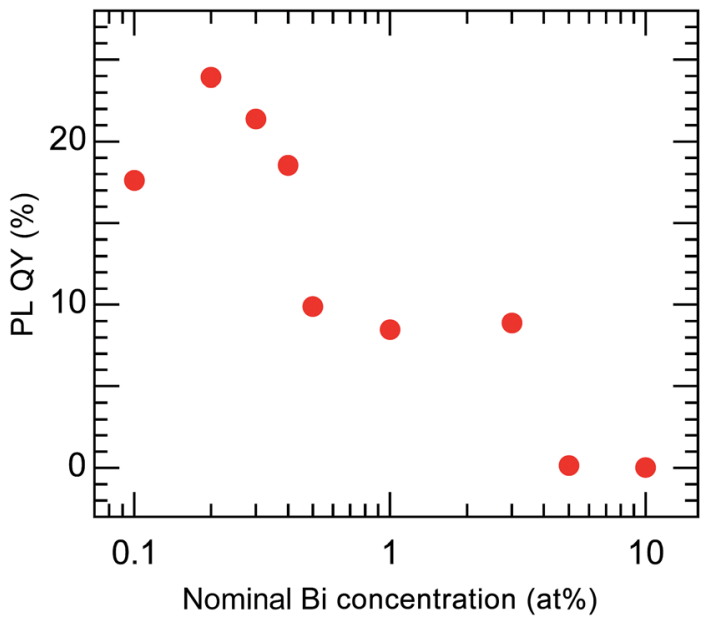

Fig. $8 \mathrm{PL} \mathrm{QY}$ of $\mathrm{Bi}^{3+}, \mathrm{Eu}^{3+}$-codoped calcined samples with varying nominal $\mathrm{Bi}$ concentrations. $\mathrm{Eu}^{3+}=2 \mathrm{at} \% . \lambda_{\mathrm{ex}}=332 \mathrm{~nm}$ and $\lambda_{\mathrm{em}}=$ $612 \mathrm{~nm}$.

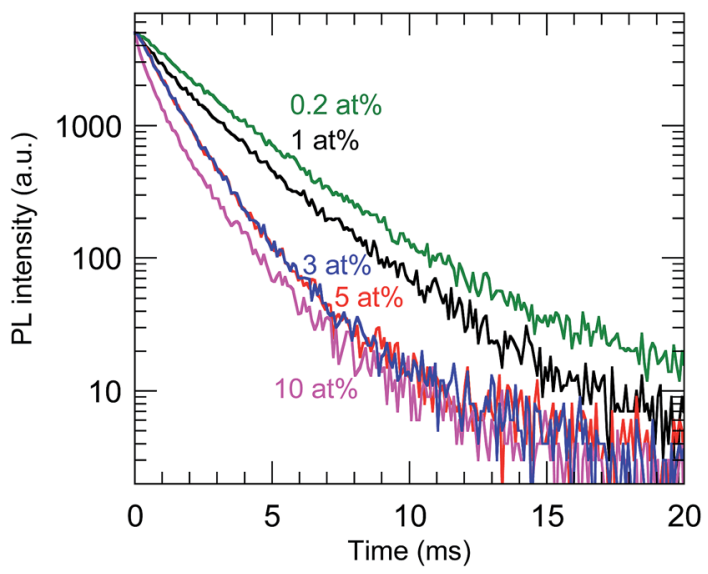

Fig. $9 \mathrm{PL}$ decay curves of the calcined samples codoped with 0.2-10 at\% $\mathrm{Bi}^{3+}$ and $2 \mathrm{at} \% \mathrm{Eu}^{3+}$. $\lambda_{\mathrm{ex}}=365 \mathrm{~nm}$ and $\lambda_{\mathrm{em}}=612 \mathrm{~nm}$.

Table 2 PL lifetimes of the calcined samples codoped with $0.2-10$ at\% $\mathrm{Bi}^{3+}$ and 2 at\% $\mathrm{Eu}^{3+}$ calculated from the decay curves

\begin{tabular}{llll}
\hline Nominal Bi (at\%) & $\tau_{1}(\mathrm{~ms})$ & $\tau_{2}(\mathrm{~ms})$ & $\tau(\mathrm{ms})$ \\
\hline 0.2 & 2.28 & 5.07 & 2.80 \\
1.0 & 1.24 & 2.77 & 2.29 \\
3.0 & 1.07 & 2.41 & 1.37 \\
5.0 & 1.06 & 2.27 & 1.37 \\
10 & 0.49 & 1.64 & 1.19 \\
\hline
\end{tabular}

where $I$ is the PL intensity at time $t, \tau_{1}$ and $\tau_{2}$ are the short and long PL lifetimes, and $A_{1}$ and $A_{2}$ are constants. The two PL lifetime components imply two different $\mathrm{Eu}^{3+}$ luminescence centers. As mentioned above, the most likely luminescent centers for the emission at $612 \mathrm{~nm}$ are $\mathrm{Eu}^{3+}$ ions at the $C_{2}$ sites and the surface sites. Generally, the surface sites have shorter lifetimes than the lattice sites because of surface defects. Therefore, $\tau_{1}$ can be assigned to the surface sites and $\tau_{2}$ to the $C_{2}$ sites. The average lifetime $\tau$ was calculated by eqn (3):



Fig. 10 Time-evolution of the PL intensity of the calcined samples codoped with $0.2-10 \mathrm{at} \% \mathrm{Bi}^{3+}$ and $2 \mathrm{at}^{3} \mathrm{Eu}^{3+}$ under continuous nearUV excitation. $\lambda_{\mathrm{ex}}=332 \mathrm{~nm}$ and $\lambda_{\mathrm{em}}=612 \mathrm{~nm}$.

$$
\tau=\left(A_{1} \tau_{1}^{2}+A_{2} \tau_{2}^{2}\right)\left(A_{1} \tau_{1}+A_{2} \tau_{2}\right)
$$

$\tau$ was found to decrease with increasing $\mathrm{Bi}^{3+}$ concentration, which confirmed that concentration quenching occurred with $\geq 0.2$ at $\% \mathrm{Bi}^{3+}$.

The time-evolution of the PL intensity of the $612 \mathrm{~nm}$ emission from the $\mathrm{Y}_{2} \mathrm{O}_{3}: \mathrm{Bi}^{3+}, \mathrm{Eu}^{3+}$ nanosheets under continuous excitation was measured to evaluate their photostability; the results are presented in Fig. 10. The initial PL intensity was highest for the calcined sample codoped with $0.2 \mathrm{at}^{\mathrm{B}} \mathrm{Bi}^{3+}$ and 2 at $\% \mathrm{Eu}^{3+}$. For the samples with the low Bi contents, the PL intensity prominently increased soon after the excitation began. For example, with 0.2 at\% $\mathrm{Bi}^{3+}$, the PL intensity increased to $120 \%$ of its initial value, and then remained constant. Such an increase in PL intensity under continuous excitation has, to the best of our knowledge, never been reported for $\mathrm{Y}_{2} \mathrm{O}_{3}: \mathrm{Bi}^{3+}, \mathrm{Eu}^{3+}$. This behavior may be attributable to the photooxidation of bismuth ions in the calcined samples. Bismuth has a variety of possible valence states, including $\mathrm{Bi}^{+}$and $\mathrm{Bi}^{2+} \cdot{ }^{33}$ If the $\mathrm{Bi}^{3+}$ ions were reduced to those species by PEI or methanol during the synthesis, the subsequent photooxidation of $\mathrm{Bi}^{+}$or $\mathrm{Bi}^{2+}$ back to $\mathrm{Bi}^{3+}$ would increase the number of excitation centers. This may be the origin of the increased PL intensity of the samples with low Bi concentrations, such as 0.2 at\%. In the samples with higher Bi concentrations, the increase in PL intensity following excitation was markedly smaller. Increasing the $\mathrm{Bi}^{3+}$ concentration would have shortened the distances between $\mathrm{Bi}^{3+}$ ions and increased the probability of energy transfer between them, a process that contributes to concentration quenching, thus suppressing the increase in PL intensity.

\section{Conclusions}

We produced $\mathrm{Y}_{2} \mathrm{O}_{3}: \mathrm{Bi}^{3+}, \mathrm{Eu}^{3+}$ nanosheets through calcining solvothermally-synthesized LYH nanosheets. XRD and TEM analysis revealed that the LYH nanosheets were composed of 
crystallites with a uniform crystallographic orientation. Their sheet-like morphology and single-crystal nature remained after calcination, while the thickness of the nanosheets decreased from $40 \mathrm{~nm}$ to $25 \mathrm{~nm}$. The PL and PLE spectra of the $\mathrm{Y}_{2} \mathrm{O}_{3}: \mathrm{Bi}^{3+}, \mathrm{Eu}^{3+}$ nanosheets exhibited red emission from $\mathrm{Eu}^{3+}$ following energy transfer from photoexcited $\mathrm{Bi}^{3+}$ to $\mathrm{Eu}^{3+}$. The $\mathrm{PL}$ QY of the $\mathrm{Y}_{2} \mathrm{O}_{3}: \mathrm{Bi}^{3+}, \mathrm{Eu}^{3+}$ nanosheets with fixed $\mathrm{Eu}^{3+}$ concentrations of 2 at\% was dependent on the Bi content, with the highest QY being 23\%, in the sample with a Bi concentration of 0.2 at\%. The PL lifetimes of the calcined samples with $\mathrm{Bi}^{3+}$ concentrations of $\geq 0.2$ at $\%$ decreased with increasing $\mathrm{Bi}$ concentration because of concentration quenching. However, for each sample, the PL intensity under continuous excitation increased over time. This may be attributable to the photooxidation of bismuth in low oxidation states following its reduction by PEI or methanol during the LYH synthesis.

\section{Acknowledgements}

This work was supported by Japan Society for the Promotion of Science KAKENHI Grant Number 15K04612.

\section{References}

1 J. Liu, X. Zou, B. Xu, H. Luo, H. Lv, L. Han and X. Yu, CrystEngComm, 2012, 14, 3149-3155.

2 A. Towata, M. Sivakumar, K. Yasui, T. Tuziuti, T. Kozuka and Y. Iida, J. Mater. Sci., 2008, 43, 1214-1219.

3 B. Lu, J. Li, T. Suzuki, M. Estili, W. Liu, X. Sun and Y. Sakka, J. Am. Ceram. Soc., 2015, 98, 1413-1422.

4 L. S. Chi, R. S. Liu and B. J. Lee, J. Electrochem. Soc., 2005, 152, J93-J98.

5 W. J. Park, S. G. Yoon and D. H. Yoon, J. Electroceram., 2006, 17, 41-44.

6 G. Ju, Y. Hu, L. Chen, X. Wang, Z. Mu, H. Wu and F. Kang, J. Electrochem. Soc., 2011, 158, J294-J299.

7 T.-S. Chan, C.-C. Kang, R.-S. Liu, L. Chen, X.-N. Liu, J.-J. Ding, J. Bao and C. Gao, J. Comb. Chem., 2007, 9, 343-346.

8 K. Ohno, Phosphors for cathode-ray tubes, Phosphor Handbook, CRC Press LLC, Boca Raton, 1999, pp. 489-498.

9 C. Strumpel, C. McCann, G. Beaucarne, G. Arkhipov, A. Slaoui, V. Svrcek and C. Canizo, Sol. Energy Mater. Sol. Cells, 2007, 91, 238-249.

10 P. Chung, H. Chung and P. Holloway, J. Vac. Sci. Technol., A, 2007, 25, 61-66.

11 N. Chander, A. F. Khan, P. S. Chandrasekhar, E. Thouti, S. K. Swami, V. Dutta and V. K. Komarala, Appl. Phys. Lett., 2014, 105, 033904.
12 C. K. Huang, Y. C. Chen, W. B. Huang, T. M. Chen, K. W. Sun and W.-L. Chang, Prog. Photovoltaics. Res. Appl., 2013, 21, 1507-1513.

13 E. Klampaftis, D. Ross, K. R. McIntosh and B. S. Richards, Sol. Energy Mater. Sol. Cells, 2009, 93, 1182-1194.

14 B. M. Ende, L. Aartsa and A. Meijerink, Phys. Chem. Chem. Phys., 2009, 11, 11081-11095.

15 Y. Iso, S. Takeshita and T. Isobe, J. Electrochem. Soc., 2012, 159, J72-J76.

16 S. Takeshita, H. Ogata, T. Isobe, T. Sawayama and S. Niikura, J. Electrochem. Soc., 2010, 157, J74-J80.

17 S. Takeshita, T. Watanabe, T. Isobe, T. Sawayama and S. Niikura, Opt. Mater., 2011, 33, 323-326.

18 H. Hara, S. Takeshita, T. Isobe, T. Sawayama and S. Niikura, Mater. Sci. Eng., B, 2013, 178, 311-315.

19 Q. Zhu, J.-G. Li, C. Zhi, R. Ma, T. Sasaki, J. X. Xu, C. H. Liu, X. D. Li, X. D. Sun and Y. Sakka, J. Mater. Chem., 2011, 21, 6903-6908.

20 H. Zhu, Y. Ma, H. Yang, P. Zhu, J. Du, C. Ji and D. Hou, J. Solid State Chem., 2010, 150, 1208-1212.

21 A. P. Jadhav, C. W. Kim, H. G. Cha, A. U. Pawar, N. A. Jadhav, U. Pal and Y. S. Kang, J. Phys. Chem. C, 2009, 113, 1360013604.

22 Q. Zhu, J.-G. Li, R. Ma, T. Sasaki, X. Yang, X. Li, X. Sun and Y. Sakka, J. Solid State Chem., 2012, 192, 229-237.

23 Q. Zhu, J.-G. Li, C. Zhi, X. Li, X. Sun, Y. Sakka, D. Golberg and Y. Bando, Chem. Mater., 2010, 22, 4204-4213.

24 F. Geng, H. Xin, Y. Matsushita, R. Ma, M. Tanaka, F. Izumi, N. Iyi and T. Sasaki, Chem.-Eur. J., 2008, 14, 9255-9260.

25 X. Wu, J.-G. Li, Q. Zhu, W. Liu, J. Li, X. Li, X. Sun and Y. Sakka, J. Mater. Chem. C, 2015, 3, 3428-3437.

26 L. Hu, R. Ma, T. C. Ozawa and T. Sasaki, Inorg. Chem., 2010, 49, 2960-2968.

27 L. Hu, R. Ma, T. C. Ozawa and T. Sasaki, Angew. Chem., Int. Ed., 2009, 48, 3846-3849.

28 Q. Zhu, J. G. Li, X. Li, X. Sun, Y. Qi, M. Zhu and Y. Sakka, Sci. Technol. Adv. Mater., 2014, 15, 14203.

29 T. Matsunaga, S. Takeshita and T. Isobe, J. Lumin., 2015, 165, 62-67.

30 S. S. Lee, B. I. Lee, S. J. Kim, S. H. Byeon and J. K. Kang, Inorg. Chem., 2012, 51, 10222-10232.

31 J. Liang, R. Ma and T. Sasaki, Dalton Trans., 2014, 43, 1035510364.

32 A. D. Yapryntsev, A. E. Baranchikov, L. S. Skogareva, A. E. Goldt, I. P. Stolyarov, O. S. Ivanova, V. V. Kozik and V. K. Ivanov, CrystEngComm, 2015, 17, 2667-2674.

33 R. Cao, M. Peng and J. Qiu, Opt. Express, 2012, 20, A977A983. 